\title{
Effects of benzoxazol and its nitro-derivatives on growth indicators and chemical composition of tomato fruits
}

\author{
C Loik G. Mukhtorov, ${ }^{1}$ Maria B. Nikishina, ${ }^{1 *}$ Evgenia V. Ivanova, ${ }^{1+}$ Yury M. Atroschenko, ${ }^{1}$ \\ Irina V. Shahkeldyan, ${ }^{1}$ and Makhmadkul B. Karimov ${ }^{2}$ \\ ${ }^{1}$ Department of Chemistry. Tula State Lev Tolstoy Pedagogical University. Lenina St., 125. \\ Tula, 300026.Russia.Phone: +7 (4872)35-78-08.E-mail: reaktiv@tspu.tula.ru \\ ${ }^{2}$ Dushanbinsky Branch of the National Research Technological University. Nazarshoeva St., 7. Dushanbe. \\ Republic of Tajikistan.Phone: +992919-410-241.E-mail: karimovm.b@mail.ru
}

\begin{abstract}
*Supervising author; ${ }^{+}$Corresponding author Keywords: germination, germination, sugar, ascorbic acid, acidity, nitrate ions, benzoxazole, 5-nitrobenzoxazole, 5,7-dinitrobenzoxazole.
\end{abstract}

\begin{abstract}
The present work is devoted to the study of the biological activity of benzoxazole, 5-nitrobenzoxazole and 5,7-dinitrobenzoxazole in relation to tomato plants. The ability of these substances to stimulate growth processes in tomato seeds, to influence the synthesis of mono- and polysaccharides, to regulate the content of ascorbic acid and the total acidity in the fruits of tomatoes has been studied. The ability of plants to accumulate nitrogen in the nitrate form under the action of benzoxazole and its nitro derivatives has also been analyzed. Thus, the possibility of improving the sowing properties and chemical characteristics of tomato plants by treating them with compounds of the benzoxazole group was studied.

In addition, an assessment of the toxicity of the studied drugs was carried out using the computer program GUSAR on-line. Predictions of bioaccumulation factor (BCF) and endotoxicity class for rats were obtained for four forms of drug administration in animals.

Earlier, the authors of the article carried out studies of the fungistatism of the considered compounds in vitro on six pathogenic fungi of various taxonomic classes.

The germination of tomato seeds treated with the tested drugs was determined in the laboratory on the 12 th day of the experiment by counting the germinated seeds. The germination values are expressed as a percentage of the total number of seeds sown.

Growing tomato plants and harvesting was carried out in open ground conditions. Plants were treated with benzoxazole and its nitro derivatives by watering with solutions with a concentration of $0.05 \mathrm{~mol} / 1$. Control plants were watered. Chemical analysis of tomato fruits was performed under laboratory conditions in accordance with GOST.

The analysis of the obtained data showed that the introduction of nitro groups into the basic structure of benzoxazole is accompanied by a significant increase in the biological activity of the synthesized compounds, which has different patterns of manifestation depending on the stage of plant development.

Thus, 5,7-dinitrobenzoxazole has the greatest stimulating effect on the growth processes in tomato seeds. While the most pronounced positive effect on the synthesis in the fruits of tomato sugars and ascorbic acid was 5-nitrobenzoxazole. For unsubstituted benzoxazole, no pronounced positive trends in the manifestation of biological activity have been identified.

Evaluation forecast using the computer program GUSAR on-line allowed to establish a low level of toxicity of the studied substances.

This work is part of the study of the biological activity of various classes of organic compounds. The effect of the test substance on the growth rate and development of agricultural plants, their chemical composition is analyzed. In addition, the fungicidal activity of these compounds is determined. Thus, the purpose of the research is the selection of substances capable of comprehensively solving the problem of obtaining and preserving the yield of crop production.
\end{abstract}

\section{References}

[1] S.O. Bondar, M.B. Nikishina, O.I. Boikova, L.L. Kirilova, E.V. Ivanova, O.S. Polovezkaya, Yu.M. Atroshchenko, and K.I. Kobrakov. The effect of organic acids on growth characteristics and 
Full Paper L.G. Mukhtorov, M.B. Nikishina, E.V. Ivanova, Yu.M. Atroschenko, I.V. Shahkeldyan, and M.B. Karimov accumulation of nitrate ions by plants of lettuce. Butlerov Communications. 2017. Vol.51. No.8. P.33-38. DOI: $10.37952 /$ ROI-jbc-01/17-51-8-33

[2] T.A. Zavershneva, M.B. Nikishina, O.I. Boykova, E.V. Ivanova, O.S. Polovezkaya, Yu.M. Atroshchenko ${ }^{1}$, and K.I. Kobrakov. Study of the effect of organic dicarboxylic acids on biometric indicators and accumulation of nitrate ions in cucumber fruits. Butlerov Communications. 2017. Vol.51. No.9. P.76-82. DOI: 10.37952/ROI-jbc-01/17-51-9-76

[3] L.G. Mukhtorov, A.M. Peshkova, L.L. Kirillova, M.B. Nikishina, E.V. Ivanova, Yu.M. Atroshchenko, and K.I. Kobrakov. Fungicidal activity of 2-aminophenol and its nitro derivatives. Butlerov Communications. 2018. Vol.56. No.10. P.156-160. DOI: 10.37952/ROI-jbc-01/18-56-10-156

[4] L.G. Mukhtorov, G.V. Pestsov, M.B. Nikishina, E.V. Ivanova, I.V. Shahkeldyan, Yu.M. Atroshchenko, and K.I. Kobrakov. Effect of nitro groups on the fungicidal activity of benzoxazole. Butlerov Communications. 2018. Vol.54. No.4. P.156-161. DOI: 10.37952/ROI-jbc-01/18-54-4-156

[5] Lagunin A, et al. QSAR Modelling of Rat Acute Toxicity on the Basis of PASS Prediction. Mol. Informatics. 2011. 30(2-3). P.241-250. 